\title{
Evaluation of Commercial Ropes Applied as Artificial Tendons in Robotic Rehabilitation Orthoses
}

\author{
Guilherme de Paula Rúbio ${ }^{1}{ }^{\mathbb{D}}$, Fernanda Márcia Rodrigues Martins Ferreira ${ }^{1}{ }^{(}$, \\ Fabrício Henrique de Lisboa Brandão ${ }^{2}$, Victor Flausino Machado ${ }^{2}$, Leandro Gonzaga Tonelli ${ }^{2}$, \\ Jordana Simões Ribeiro Martins ${ }^{3}\left(\mathbb{D}\right.$ and Renan Fernandes Kozan ${ }^{4}$ \\ and Claysson Bruno Santos Vimieiro $1,2,3 *$ iD \\ 1 Graduate Program in Mechanical Engineering, Universidade Federal de Minas Gerias, Belo Horizonte, MG, \\ Brazil; guilhermeprubio@gmail.com (G.d.P.R.); fernandaferreira.to@gmail.com (F.M.R.M.F.) \\ 2 Department of Mechanical Engineering, Universidade Federal de Minas Gerias, Belo Horizonte, MG, Brazil; \\ fabriciohlisboa@gmail.com (F.H.d.L.B.); victor.fmachado72@gmail.com (V.F.M.); ltonellig@gmail.com (L.G.T.) \\ 3 Graduate Program in Mechanical Engineering, Pontifícia Universidade Católica de Minas Gerais, \\ Belo Horizonte, MG, Brazil; martinsjsr@gmail.com \\ 4 Department of Electrical Engineering, Universidade Federal de Minas Gerias, Belo Horizonte, MG, Brazil; \\ renankozan@gmail.com \\ * Correspondence: claysson@pucminas.br; Tel.: +55-31-99161-1320
}

Received: 28 December 2019; Accepted: 23 January 2020; Published: 31 January 2020

Featured Application: This study can be used as a reference for works that develop active orthoses or prostheses that use artificial tendons to move the fingers, helping in the process of defining these tendons.

\begin{abstract}
This study aims to present the design, selection and testing of commercial ropes (artificial tendons) used on robotic orthosis to perform the hand movements for stroke individuals over upper limb rehabilitation. It was determined the load applied in the rope would through direct measurements performed on four individuals after stroke using a bulb dynamometer. A tensile strength test was performed using eight commercial ropes in order to evaluate the maximum breaking force and select the most suitable to be used in this application. Finally, a pilot test was performed with a user of the device to ratify the effectiveness of the rope. The load on the cable was $12.38 \mathrm{kgf}(121.4 \mathrm{~N})$ in the stroke-affected hand, which is the maximum tensile force that the rope must to supports. Paragliding rope (DuPont ${ }^{\mathrm{TM}}$ Kevlar ${ }^{\circledR}$ ) supporting a load of $250 \mathrm{~N}$ at a strain of $37 \mathrm{~mm}$ was selected. The clinical test proved the effectiveness of the rope, supporting the requested efforts, without presenting permanent deformation, effectively performing the participant's finger opening.
\end{abstract}

Keywords: orthosis; biomechanics; tensile strength test; robotic therapy

\section{Introduction}

Stroke is the world's leading cause of death and disability [1]. with 6.7 million deaths per year, estimated to be the second leading cause of death by the year $2030[2,3]$.

Stroke is a clinical syndrome caused by a reduction in blood perfusion in brain structures and is characterized by disturbances in brain function [4]. About $57 \%$ of individuals, after having a stroke, have some of limitations in daily activities and more than $50 \%$ of these individuals have functional impairment, thus requiring some external help to perform functional tasks [5]. The prevalent motor deficits presented are paralysis (hemiplegia) or weakness (hemiparesis) of body contralateral half to stroke injury [6]. Clinically, muscle weakness, muscle tone abnormality, movement control deficiency, body composition changes of the extremities with loss of muscle and bone mass [7], postural 
alteration, lack of mobility, abnormal synergistic patterns and loss or reduction of motor coordination can also be observed [8].

An innovative and promising rehabilitation alternative capable of enhancing the motor and functional capacity of individuals after stroke is the robotic therapy [9]. It uses robotic orthoses, which is mechatronic equipment ranging from the creation of artificial limbs, to robots that assist in rehabilitation or hospital or residential care [10].

The great advantage of using these devices is the high degree of repeatability and the performance of intensive activities with less professional supervision, using a simple routine of pre-programmed robot rehabilitation activities [8,11-13]. Numerous systematic reviews have been performed showing the efficiency in using these devices to rehabilitate individuals [12,14-18]. An Improvement in short and long-term proximal end (shoulder and elbow) motor control has been observed in acute and chronic post-stroke patients, using these devices [12,17]. A combination of traditional methods and robotic therapy in some stages of stroke recovery can produce a significant improvement in elbow and shoulder motor recovery $[16,18]$. An improvement in daily life activity, arm function and muscle strength has also been observed [15], as well as minor effects on motor control and mild effects on muscle strength compared with other short-term interventions using robotic therapy [14]. A combination of these devices with brain-computer interfaces has been also used to improve the rehabilitation ability of individuals after stroke, thus proving the effectiveness of these robots during therapy sessions [19].

Several devices have also been developed to rehabilitate or assist upper limb function, such as MIT-Manus [20], ARMin III [21], MIME [22], BI-MANU-TRACK [23], ARM Guide [24] and NeReBot [25]. In Brazil, the Laboratório de Bioengenharia da Universidade Federal de Minas Gerais (LabBio-UFMG), located in Belo Horizonte/MG, developed a robotic orthosis for upper limb rehabilitation of post stroke individuals [26,27].

Currently is desire the development of soft robots, made by tissue, or elastic polymers [28]. In this way, mechanical tendons or soft actuators act like a human tendon performing the exoskeleton actuation function, while the hand and fingers perform the strutural function [29]. These devices often use springs, cables, elastics, ropes or elastic wires, making the same fuction of artificial tendons, to transmit movement to the paralyzed muscles, through traction and relaxation of them. In the Exo-Glove [29] (Figure 1b) a Bowden cable, frequently used like a bicycle brake cable, was used to perform the artificial tendon function and control the fingers movement, your choice was due to a teflon coating which protects the steel cable. In the Xiloyannis et al. [30,31] work a Bowden cable was used to transmit de motor force to the artificial tendon, but in the first a Kevlar rope was used in the artifical tendon function and in the second another cable steel was used for this. In the Hero system [32] (Figure 1a) a tie up, made by plastic, was used and a simple rope was used in the previously version of the LabBio hand orthesis [33] (Figure 1c).

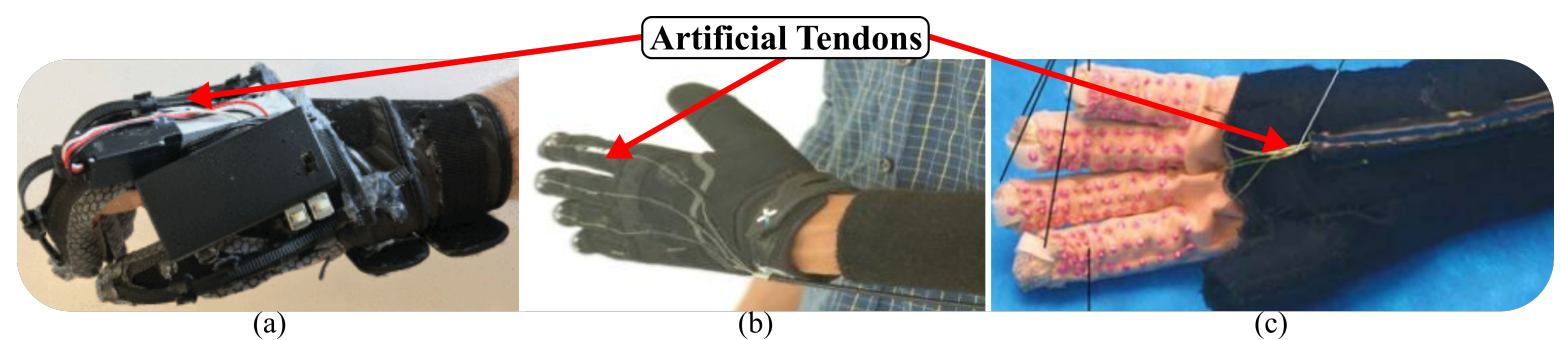

Figure 1. Use of artificial tendon in: (a) Hero orthosis, (b) hand exoskeleton and (c) LabBio orthosis. Adapted from Cherian et al. [29], Yurkewich et al. [32], Rocha [33].

These artificial tendons must be able to withstand heavy loads, have low strain, ease of handling and good fit for the user limb, ensuring safe use of the equipment. To achieve this a correct analysis of each cable must be made, through tests that prove the correct functioning of the tendons. Thus, this paper aims 
to present the design, selection and testing of commercial ropes that were used to generate the hand movements of a robotic orthosis for upper limb rehabilitation of individuals after stroke.

\section{Methodology}

\subsection{Device}

The orthosis developed in (LabBio-UFMG) is portable, low cost and low weight composed by a module with glove and artificial fingers and phalanxes, witch are connected to ropes (artificial tendons) that are able to open the user's fingers. The rope is pulled through a power screw system coupled to a motor, which executes and controls the motions. The rope was attached to the transmission system through a support fixed by a bolt (Figure 2).

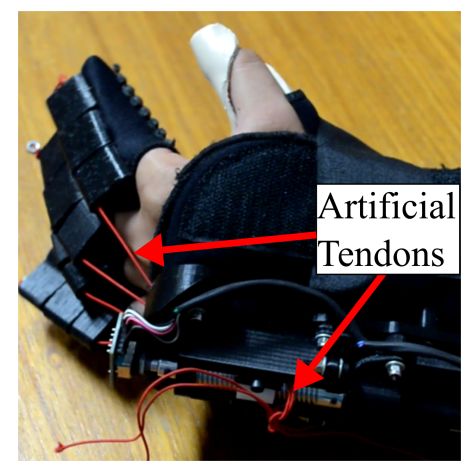

Figure 2. Orthosis with artificial tendons use.

The artificial phalanges limit the users' phalanges movement avoiding anything greater than physiological amplitudes. For fingers' opening movement, the artificial tendon was tensioned and the distal artificial phalanx was pulled, in that way, performing a rotation about the distal articulation axis. This movement was performed until the distal artificial phalanx collided with the middle artificial phalanx. Keeping the traction in the artificial tendon, a rotation about the middle articulation axis was performed until the collision between middle and proximal artificial phalanges. The rotation now occurred about the proximal articulation axis until the transmission system nut actuated the travel limiter sensor present in the system, so the fingers' opening completed movement was performed (Figure 3). The closing movement of the fingers was performed passively, taking advantage of the user's ability to perform this movement. Due to this, the artificial tendon was designed to support the traction during the fingers opening movement.

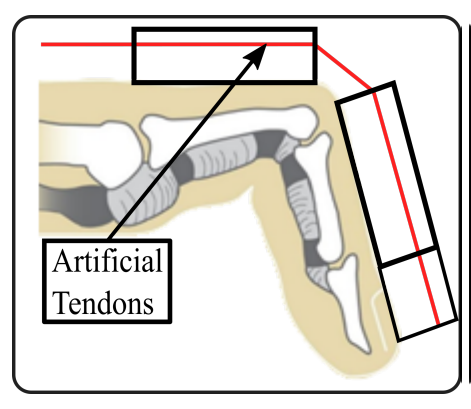

(a)

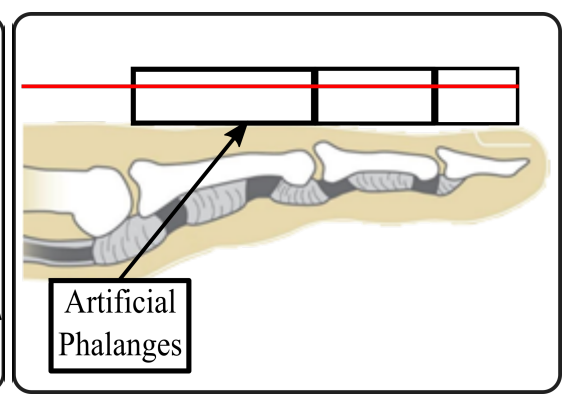

(b)

Figure 3. Schematic representation of the (a) opening and (b) closing fingers movement by the device. Adapted from Rúbio et al. [27].

Before to the operation started, with the orthosis dressed up, the operator commanded the actuator to the fully fingers opening setup with the bracket screw loose.Upon reaching the position, the operator pulled the ropes, with the user's hand fully opening, until they were on full traction, and tightened 
the fastener screw, thus ensuring the correct performance of the system. All position and speed control was made through an application developed for the Android ${ }^{\circledR}$ system and a microcontrolled electronic circuit by a STM32F103.

\subsection{Volunteers}

The volunteers were recruited, for a pilot test with the device, through a public call issued by stroke associations, rehabilitation centers, hospitals and social media in the city of Belo Horizonte, Minas Gerais in December 2016. They were selected according to the inclusion and exclusion criteria and informed about the study objectives. Those who agreed to participate signed the informed consent form. The study project was approved by the Universidade Federal de Minas Gerais Research Ethics Committee (CAAE Registry: 22207213.5.0000.5149).

Inclusion criteria were: age greater or equal than 18 years with left unilateral stroke and chronic impairment diagnosis (minimum six months after stroke) [34]; present hemiparesis with reduced upper limb motor function (elbow and fingers incomplete flexion and extension movements, presenting arm and hand in the 4th Brunnstrom phase) [35]; present at least $45^{\circ}$ of the shoulder flexion and abduction, complete passive movement of the elbow, hand and finger joints without compromised sensitivity measure by the Fugl-Meyer scale [36]; present muscle tone alteration from mild to moderate, measured through the Modified Ashworth Scale [37]; present absence of severe cognitive deficits, evaluated by the Brazilian version of the Mini-Mental State Examination [38]. The exclusion criteria in the study were: flaccidity in the affected upper limb; severe neurological, orthopedic or rheumatologic impairment before the stroke that may interfere with the performance task; severe cognitive impairment (global aphasia, attention deficit, neglect) that limits understanding of commands or conclusion of experimental tasks; severe pain in the affected upper limb, measured using the Visual Analogue Scale (VAS) (> 8 on a scale from 0 to 10); opened skin injuries where the device would be attached; having used Botox in the last three months for spasticity or other medicines known to increase motor recovery; having participated in the last three months of another research study to improve upper limb function.

Four individuals were selected to participate in the study. Their characteristics are presented in Table 1.

Table 1. Volunteers characteristics.

\begin{tabular}{rccccl}
\hline Participant & Sex & Age & Dominance & Post Stroke Time & Finger Spasticity Level * \\
\hline 1 & Male & 73 & Right & 53 months & 1 \\
2 & Male & 38 & Right & 113 months & 2 \\
3 & Female & 25 & Left & 48 months & 2 \\
4 & Female & 48 & Right & 24 months & 1 \\
\hline
\end{tabular}

$\left(^{*}\right)$ Spasticity assessed using the Ashworth Scale.

\subsection{Artificial Tendons Design and Selection}

For the artificial tendons design and selection used in the hand module, some design steps were required. The first was the determination of the loads to which the ropes were subjected; thereafter a tensile strength test using various commercial ropes to evaluate and determine what would best fit the use; and finally a pilot test with the volunteers to confirm the effectiveness of the rope as an artificial tendon.

\subsubsection{Applied Loads Determination}

To determine the traction force that the rope would be subjected, direct measurements were performed on the four volunteers with a New Saehan Squeeze Dynamometer-SH5008 bulb-type dynamometer. Normative anthropometric data were not used for this determination because individuals after stroke 
present abnormality in tone, which implies hypotonia in the development and subsequent hypertonia in these individuals. This hypertonia can lead to spasticity, which implies speed-dependant increase in muscle tone, thereby increasing myotactic reflex, postural changes and stereotyped movements, which leads to a reduction in the range of joint motion, pain, muscles limb activities limitation and consequently hinders the performance of daily functional activities [39,40]. Because of that, these individuals present a lower grip strength than normative anthropometric data, which present an average of $44.2 \mathrm{kgf}$ for men and $31.6 \mathrm{kgf}$ for women when using the dominant hand [35].

As users of this equipment present difficulties only in the fingers opening movement, the maximum force required to the rope was greater or equal than the maximum grip strength of the hand affected, that is, pulling the rope. The movement of finger closure was given passively, taking advantage of the spasticity presented by the individuals and the ability to close the fingers preserved.

To measure the grip strength, each participant squeezed the dynamometer body as tightly as possible for three consecutive times and an average of the strength measured was calculated. The traction force applied to the selected cable was determined to be the highest of the average forces measured, thus ensuring that the rope safely supports the required loads.

\subsubsection{Tensile Strength Test}

After defining the applied traction force, the rope used was selected. For this, a set of eight different commercial ropes were subjected to a tensile strength test, until their rupture, to determine the maximum supported force and the strain of each one. The first guarantees the system's operation, and must have a value greater or equal than the volunteers highest average grip force, which was the maximum traction load defined for the project. Already the strain ensures the device a degree of repeatability, since one of the great advantages of robotic therapy is the ability to perform the same movements over and over again on the patient $[8,11,12]$, the selected rope must not have permanent strain after performing one or more actions, to ensure the fingers correct position.

The selected ropes to the tests should have a diameter equal or less than $1.25 \mathrm{~mm}$ to easily couple the rope in the nut and artificial phalanges without raising the device components size and weight. Furthermore, they usually used in hight loads applications and could be easily found in the regional market due to the fabrication costs. Their characteristics are presented in the Table 2.

Table 2. Ropes characteristic.

\begin{tabular}{|c|c|c|c|}
\hline Manufacturer & Product & Material & Diameter $[\mathrm{mm}]$ \\
\hline D'Addarío & $\begin{array}{c}\text { Guitar String } \\
\text { D }(85 / 15)\end{array}$ & Brass & 0.64 \\
\hline D’Addarío & $\begin{array}{l}\text { Guitar String } \\
\text { E }(85 / 15)\end{array}$ & Brass & 0.23 \\
\hline D’Addarío & $\begin{array}{l}\text { Guitar String } \\
\text { B }(85 / 15)\end{array}$ & Brass & 0.30 \\
\hline D’Addarío & $\begin{array}{l}\text { Guitar String } \\
\text { A }(85 / 15)\end{array}$ & Brass & 0.89 \\
\hline D’Addarío & $\begin{array}{l}\text { Guitar String } \\
\text { G }(85 / 15)\end{array}$ & Brass & 0.38 \\
\hline D’Addarío & $\begin{array}{l}\text { Guitar String } \\
\text { E }(85 / 15)\end{array}$ & Brass & 1.14 \\
\hline TufLine XP & Fishing line & Spectra ${ }^{\circledR}$ & 0.48 \\
\hline SOL Paragliders & Paragliding rope & DuPont $^{\mathrm{TM}}$ Kevlar $^{\circledR}$ & 1.00 \\
\hline
\end{tabular}

The tests were performed at the Structural Analysis Laboratory of the Pontifícia Universidade Católica de Minas Gerais, using the EMIC 23-5D tensile testing machine, which has a maximum load capacity of up $5 \mathrm{KN}$ and clamps for specimen fixation. For the attachment of the ropes, a tie was used, where the cable was tied to the machine's claws ends, using a simple knot. With the cable 
properly fixed, the upper clamp was adjusted to an initial height of $300 \mathrm{~mm}$, thus allowing a usable wire clearance of $255 \mathrm{~mm}$ and a maximum test height of $600 \mathrm{~mm}$.

For control and data acquisition, Tesc Version 3.04 software was used. The test parameters were then defined in the software, which were the "Rectangular Tie Pull" method, the type of material tested and the rope diameter analyzed. The test was initiated by the operator, and the machine gradually increased the applied force automatically until the sample rupture was reached. With the test finished, the software generated the strain and force plots with the value measured. Several tests were performed in order to stabilize the values of force and strain obtained, since the desired curve for each rope should have similar behaviors, without great variability in their force values by strain. However a great variability in the values found were observed, mainly due to the way the ropes were attached to the claw, which often fails to fix them sometimes loosening the knot made which altered the obtained data and thus several tests were needed. The results presented took into account the tests that behaved with greater similarity for each rope.

\subsubsection{Pilot Test}

With the rope selected, a device functionality test was performed with the four volunteers to approve this rope like artificial tendons. Only the results of one of the volunteers (participant 3) was shown, because this participant presented one of the highest hand spasticity values, so if the tendons could open their fingers efficiently, all of the individuals, with a spasticity lower of equal than his, would be also able to open their fingers.

The opening and closing movement of the fingers (complete extensions and flexions) were performed several times to verify if the artificial tendon supported the loads during the whole movement. Partial openings were also made in order to verify the degree of precision of the system by measuring the opening angle of the hand using a plastic PVC Carci finger goniometer. In addition, it was verified that the cable did not suffer any permanent strain during its operation.

\section{Results}

\subsection{Applied Loads Determination}

With the data of volunteers grip strength (Table 3 ), the highest average grip strength observed was equal to $17.83 \mathrm{kgf}(174,91 \mathrm{~N})$ in the hand afected by the stroke. Therefore this is the maximum traction force that the rope used should support.

Table 3. Unaffected and affected limb grip strength of volunteers.

\begin{tabular}{|c|c|c|c|c|c|c|}
\hline \multirow[b]{2}{*}{ Participant } & \multicolumn{2}{|c|}{ Measured } & \multicolumn{2}{|c|}{ Average } & \multicolumn{2}{|c|}{ Standard Deviation } \\
\hline & $\begin{array}{c}\text { Unaffected } \\
\text { [kgf] }\end{array}$ & $\begin{array}{c}\text { Affected } \\
\text { [kgf] }\end{array}$ & $\begin{array}{l}\text { Unaffected } \\
\text { [kgf] }\end{array}$ & $\begin{array}{c}\text { Affected } \\
\text { [kgf] }\end{array}$ & $\begin{array}{l}\text { Unaffected } \\
{[\text { kgf }]}\end{array}$ & $\begin{array}{c}\text { Affected } \\
\text { [kgf] }\end{array}$ \\
\hline \multirow{3}{*}{1} & 36 & 9 & & & & \\
\hline & 39 & 12 & 38.67 & 11.00 & 2.52 & 1.73 \\
\hline & 41 & 12 & & & & \\
\hline \multirow{3}{*}{2} & 54 & 18 & & & & \\
\hline & 49 & 18 & 49 & 17.83 & 5 & 0.29 \\
\hline & 44 & 17.5 & & & & \\
\hline \multirow{3}{*}{3} & 38 & 15 & & & & \\
\hline & 38 & 10 & 38.67 & 13.33 & 1.15 & 2.89 \\
\hline & 40 & 15 & & & & \\
\hline \multirow{3}{*}{4} & 34.5 & 6 & & & & \\
\hline & 37 & 9 & 33.83 & 7.33 & 3.55 & 1.53 \\
\hline & 30 & 7 & & & & \\
\hline Average & & & 40.04 & 12.38 & 6.45 & 4.28 \\
\hline
\end{tabular}




\subsection{Tensile Strength Test}

The TufLine XP fishing line behaved heterogeneously, as shown in the three force $\mathrm{x}$ strain curves below (Figure 4). It presented the maximum strength range between 45 and $140 \mathrm{~N}$ and a strain between 14 and $39 \mathrm{~mm}$ approximately.

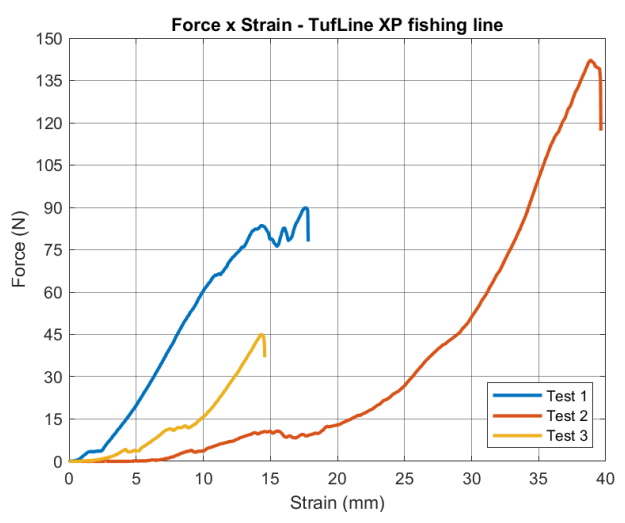

Figure 4. Force $x$ strain curves TufLine XP fishing line.

The guitar strings tested, showed a more consistent behavior, and were analyzed as shown in Figure 5. Only one curve force $x$ strain for each string was shown, due to close behavior of the curves obtained by the tests. Among the guitar strings submitted to the tensile strength test, the one that presented the best result was the $\mathrm{D}$ string $(0.64 \mathrm{~mm}$ in diameter), it presents approximately a $37 \mathrm{~mm}$ of strain, when it is pulled at $200 \mathrm{~N}$ force. This value is higher than the global average grip force in the volunteers $(12.38 \mathrm{kgf}$ or $121.45 \mathrm{~N})$ and the maximum traction force determined in the project $(174.91 \mathrm{~N})$. The ropes did not perform as expected, there was no proportional increase in the maximum tensile strength relative to the increase in the diameter of the rope. This is because, in order to change the musical notes (frequencies), in addition to increasing the diameter, changes in the string structures are necessary.
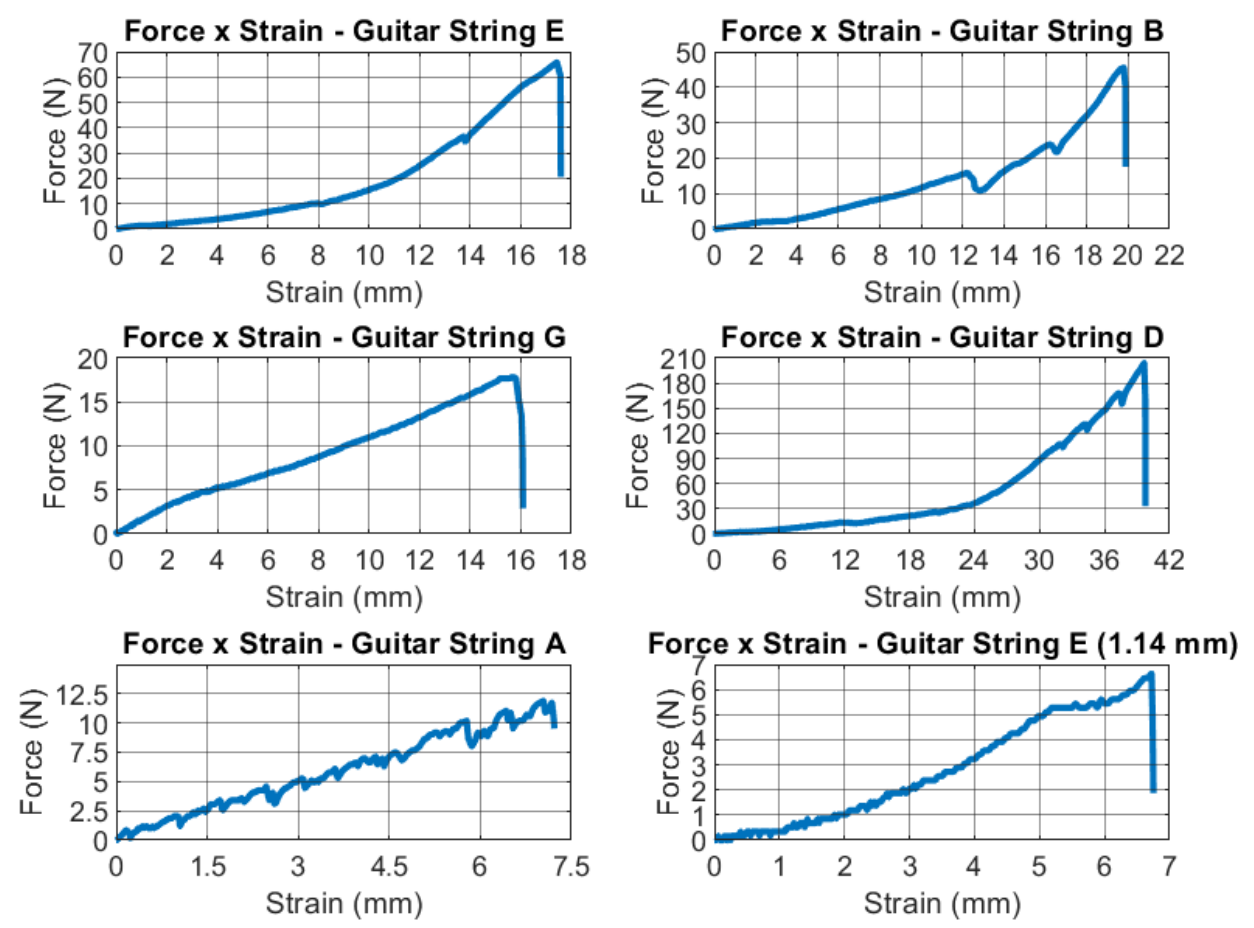

Figure 5. Force x strain curves of: Guitar String E, Guitar String B, Guitar String G, Guitar String D, Guitar String A, Guitar String E (1.14 mm). 
The last rope analyzed was the SOL Paragliders paragliding rope. The force $\mathrm{x}$ strain curves shown (Figure 6) to demonstrate the more stable behavior of the paragliding rope than the fishing line. It withstood high tensile loads between $225 \mathrm{~N}$ and $280 \mathrm{~N}$ and maximum strain between $33 \mathrm{~mm}$ and $35 \mathrm{~mm}$. In addition, the generated curves present greater congruence of values for the elastic, plastic and rupture limit regions compared to the other lines submitted to the test.

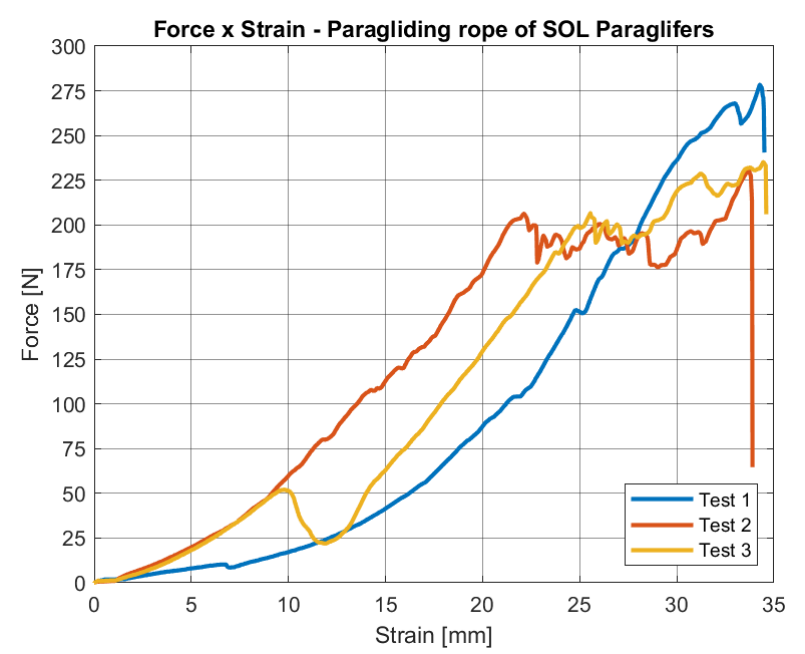

Figure 6. Force $x$ strain curves of paragliding rope of SOL Paragliders.

\subsection{Pilot Test}

With the artificial tendon selected, it was then possible to use it with a post stroke individual to validate its application. As shown in Figure 7, the participant's finger opening, using the orthosis, was satisfactory, the full opening was performed, which was not possible naturally, through voluntary control. As shown in the Figure 7a, the spasticity prevented the volunteer's hand opening movement, which at the same time performed wrist pronation due to stroke sequelae. With the orthosis (Figure $7 \mathrm{~b}$ ), pronation was no longer performed and the full opening movement of the hand was performed, proving the functionality of the device for this individual.

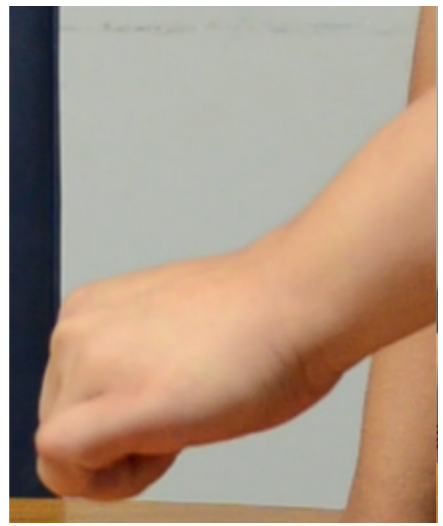

(a)

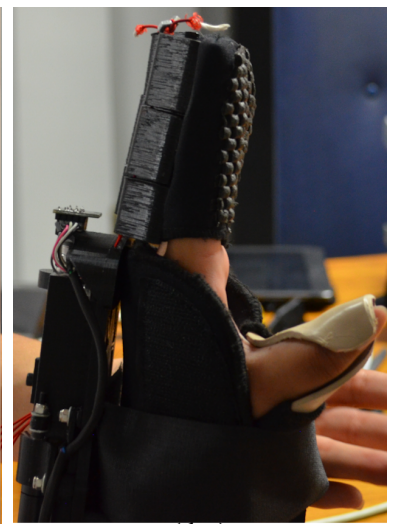

(b)

Figure 7. Participant's finger openings of (a) naturally form and (b) using the orthosis.

Making repeated partial openings of $80^{\circ}, 60^{\circ}$ and $40^{\circ}$ (Figure 8), it was observed that the fingers presented a consistency and precision in the opening angle, showing that the use of this type of rope can satisfactorily perform as an artificial tendon in robotic orthoses for individuals after stroke. It is important to emphasize that the repeated use of the equipment did not generate permanent strains in the rope, being able to execute without variations the same amount of opening requested. 


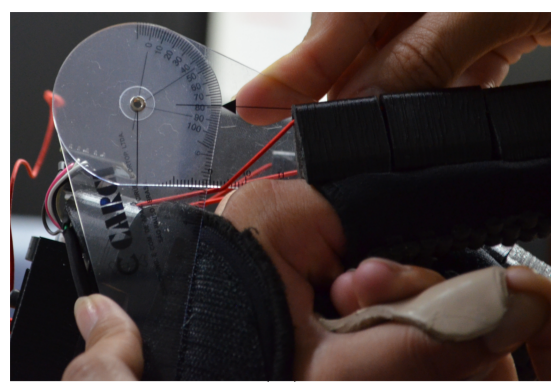

(a)

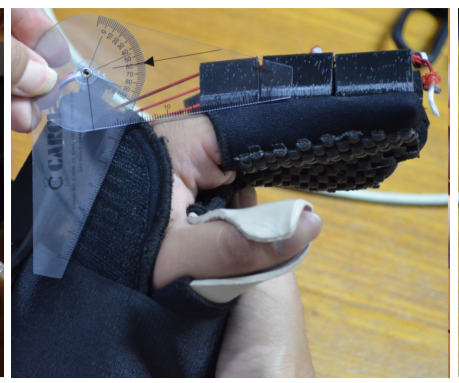

(b)

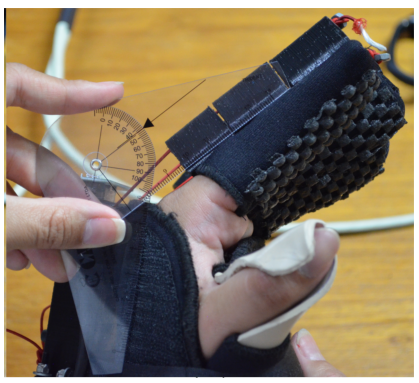

(c)

Figure 8. Fingers aperture at (a) $80^{\circ}$, (b) $60^{\circ}$ and (c) $40^{\circ}$.

\section{Discussion}

Results of the volunteers grip force measures confirm that they have a strength lower than that of typical individuals. Normative data indicate that healthy individuals had an average dominant hand grip force of $28.4 \pm 9.7 \mathrm{kgf}$ for women and $40.3 \pm 14.3 \mathrm{kgf}$ for men [41]. The change in post-stroke individuals grip force is related to the motor deficits found after the brain injury, which result from the injury to the upper motor neurons that control the distal and proximal muscles, generating a decrease in the activation of some muscle groups [42]. In addition, there is the presence of spasticity, could cause postural changes in the upper limb, which, if not corrected it generate deformities, affecting even the joints and muscles viscoelastic properties and the tendons integrity. Therefore, based on the studies of Wu et al. [43,44], we can use a high resolution ultrasound as an alternative to check these phenomena and select the most suitable cable to be used in robotic orthoses.

It can be noted in the fishing line tensile strength test (Figure 4), that there is a variability in its behavior, presented maximum traction strength below than the desired. In addition to inconsistent behavior, it is difficult to handle and could difficulty in properly adjusting tendons before orthosis operation.

The D'Addarío (85/15 bronze) guitar strings (Figure 5), despite their smallest strain, suffered some damage with the application of low force, once their constitution was related to the sound and not to the material resistance. Its structure broke internally or suffered cracks with low loads, which can be seen with a simple visual inspection.

The paragliding rope showed the highest tensile strength among the tested ropes (Figure 6), breaking through the external structure destruction, with a smoothly break.

Thus, given the analysis of data obtained in the tests performed with different ropes, the conclusion was that the most suitable for use in robotic orthosis is the paragliding rope which meets the pre-established criteria of: strength, diameter and cost. (DuPont ${ }^{\mathrm{TM}}$ Kevlar $^{\circledR}$ ). The rope presented an easy handling and greater security due to values of resistance to traction superior to the other ropes, and due to its form of rupture, since the others present a whip when broken.

The pilot test confirmed the consistency and precision in the opening angle using this rope, showing the satisfactory use as an artificial tendon in robotic orthoses. This system makes it possible to efficiently open and close the post-stroke individuals fingers, since a significant proportion of individuals with physical sequel resulting from stroke, remains with problematic or unsatisfactory manual function return [45]. With the use of artificial tendons in the orthosis, there is an increase in functional skills, facilitating the daily activities performance, such as reaching, picking up and holding objects, using tools such as a cell phone, eating, dressing and performing personal care in a general way. This significantly impacts the patient's life, improving his independence, self-esteem and life quality.

\section{Conclusions}

The use of artificial tendons applied to upper limb orthoses is one of the ways to effectively perform fingers opening of the individual. As shown in this study, commercial ropes can be used for this purpose as long as they support the requested loads without presenting a permanent strain. 
We analyzed eight ropes to act as artificial tendon and withstand a tensile load of $121.4 \mathrm{~N}$. Of these, the paragliding rope manufactured by SOL Paragliders showed the best performance for this purpose, withstanding a load of $250 \mathrm{~N}$ at approximately 30 to $35 \mathrm{~mm}$ of strain. When used in the device, in an individual after stroke, it was effective for application, being able to perform the task without breaking, and maintaining the degree of repeatability, i.e., did not suffer permanent strain, which would affect the equipment degree of repetition, validating its use as an artificial tendon.

Author Contributions: Conceptualization: G.P.R., F.M.R.M.F. and C.B.S.V.; Data curation: F.H.d.L.B., V.F.M., L.G.T.; Writing and editing: G.d.P.R., F.M.R.M.F., J.S.R.M. and C.B.S.V.; Supervision: R.F.K. and C.B.S.V.; Project administration: C.B.S.V. All authors have read and agreed to the published version of the manuscript.

Funding: This research was funded by Financiadora de Estudos e Projetos (FINEP: 01.12.0476.00), Fundação de Amparo à Pesquisa do Estado de Minas Gerais (FAPEMIG) and Coordenação de Aperfeiçoamento de Pessoal de Nível Superior (Capes): finance code 001.

Acknowledgments: The authors would like to thank the Universidade Federal de Minas Gerais, Pontifícia Universidade Católica de Minas Gerais and the Graduate Program in Mechanical Engineering for the support available to carry out this project.

Conflicts of Interest: The authors declare no conflict of interest.

\section{References}

1. GBD 2015 Neurological Disorders Collaborator Group. Global, regional, and national burden of neurological disorders during 1990-2015: A systematic analysis for the Global Burden of Disease Study 2015. Lancet Neurol. 2017, 16, 877-897. [CrossRef]

2. WHO. Health Statistics and Information Systems-Projections of Mortality and Causes of Death, 2015 and 2030. 2013. Available online: http://www.who.int/healthinfo/global_burden_disease/projections/em (accessed on 22 November 2018).

3. WHO. The top 10 causes of death. 2014. Available online: http://www.who.int/mediacentre/factsheets/fs310/em (accessed on 22 November 2018).

4. Royal College of Physicians. National Clinical Guidelines for Stroke, 5 ed.; Intercollegiate Stroke Working: London, UK, 2016.

5. Mayo, N.E.; Wood-Dauphinee, S.; Côté, R.; Durcan, L.; Carlton, J. Activity, participation, and quality of life 6 months poststroke. Arch. Phys. Med. Rehabil. 2002, 83, 1035-1042. [CrossRef]

6. O'Sullivan, S.B.; Schmitz, T.J. Physical Rehabilitation, 5 ed.; F.A. Davis Company: Philadelphia, PA, USA, 2006; p. 1383.

7. Chang, K.V.; Wu, W.T.; Huang, K.C.; Han, D.S. Segmental body composition transitions in stroke patients: Trunks are different from extremities and strokes are as important as hemiparesis. Clin. Nutr. 2019. [CrossRef]

8. Poli, P.; Morone, G.; Rosati, G.; Masiero, S. Robotic Technologies and Rehabilitation: New Tools for Stroke Patients' Therapy. BioMed Res. Int. 2013, 2013, 1-8. [CrossRef]

9. Liepert, J.; Uhde, I.; Graf, S.; Leidner, O.; Weiller, C. Motor cortex plasticity during forced-use therapy in stroke patients: A preliminary study. J. Neurol. 2001, 248, 315-321. [CrossRef]

10. Maciejasz Pawełand Eschweiler, J.; Gerlach-Hahn, K.; Jansen-Troy, A.; Leonhardt, S.; Maciejasz, P.; Eschweiler, J.; Gerlach-Hahn, K.; Jansen-Troy, A.; Leonhardt, S. A survey on robotic devices for upper limb rehabilitation. J. NeuroEng. Rehabil. 2014, 11,3. [CrossRef]

11. Duret, C.; Grosmaire, A.G.; Krebs, H.I. Robot-Assisted Therapy in Upper Extremity Hemiparesis: Overview of an Evidence-Based Approach. Front. Neurol. 2019, 10. [CrossRef]

12. Kwakkel, G.; Kollen, B.J.; Krebs, H.I. Effects of Robot-Assisted Therapy on Upper Limb Recovery After Stroke: A Systematic Review. Neurorehabil. Neural Repair 2008, 22, 111-121. [CrossRef] [PubMed]

13. Yozbatiran, N.; Francisco, G.E. Robot-assisted Therapy for the Upper Limb after Cervical Spinal Cord Injury. Phys. Med. Rehabil. Clin. North Am. 2019, 30, 367-384. [CrossRef] [PubMed]

14. Ferreira, F.M.R.M.; Chaves, M.E.A.; Oliveira, V.C.; Van Petten, A.M.V.N.; Vimieiro, C.B.S. Effectiveness of robot therapy on body function and structure in people with limited upper limb function: A systematic review and meta-analysis. PLoS ONE 2018, 13, e0200330. [CrossRef] [PubMed] 
15. Mehrholz, J.; Pohl, M.; Platz, T.; Kugler, J.; Elsner, B. Electromechanical and robot-assisted arm training for improving activities of daily living, arm function, and arm muscle strength after stroke. Cochrane Database Syst. Rev. 2018. [CrossRef] [PubMed]

16. Norouzi-Gheidari, N.; Archambault, P.S.; Fung, J. Effects of robot-assisted therapy on stroke rehabilitation in upper limbs: Systematic review and meta-analysis of the literature. J. Rehabil. Res. Develop. 2012, 49, 479. [CrossRef] [PubMed]

17. Prange, G.B.; Jannink, M.J.A.; Groothuis-Oudshoorn, C.G.M.; Hermens, H.J.; IJzerman, M.J. Systematic review of the effect of robot-aided therapy on recovery of the hemiparetic arm after stroke. J. Rehabil. Res. Develop. 2006, 43, 171. [CrossRef] [PubMed]

18. Veerbeek, J.M.; Langbroek-Amersfoort, A.C.; van Wegen, E.E.H.; Meskers, C.G.M.; Kwakkel, G. Effects of Robot-Assisted Therapy for the Upper Limb After Stroke. Neurorehabil. Neural Repair 2017, 31, 107-121. [CrossRef] [PubMed]

19. Lee, J.; Mukae, N.; Arata, J.; Iihara, K.; Hashizume, M. Comparison of Feature Vector Compositions to Enhance the Performance of NIRS-BCI-Triggered Robotic Hand Orthosis for Post-Stroke Motor Recovery. Appl. Sci. 2019, 9, 3845. [CrossRef]

20. Krebs, H.; Hogan, N.; Aisen, M.; Volpe, B. Robot-aided neurorehabilitation. IEEE Trans. Rehabil. Eng. 1998, 6, 75-87. [CrossRef]

21. Klamroth-Marganska, V.; Blanco, J.; Campen, K.; Curt, A.; Dietz, V.; Ettlin, T.; Felder, M.; Fellinghauer, B.; Guidali, M.; Kollmar, A.; et al. Three-dimensional, task-specific robot therapy of the arm after stroke: A multicentre, parallel-group randomised trial. Lancet Neurol. 2014, 13, 159-166. [CrossRef]

22. Lum, P.; Burgar, C.; Van Der Loos, M.; Shor, P.; Majumbar, M.; Yap, R. MIME robotic device for upper-limb neurorehabilitation in subacute stroke subjects: A follow-up study. J. Rehabil. Res. Dev. 2006, 45, 631,642. [CrossRef]

23. Hesse, S.; Schulte-Tigges, G.; Konrad, M.; Bardeleben, A.; Werner, C. Robot-assisted arm trainer for the passive and active practice of bilateral forearm and wrist movements in hemiparetic subjects. Arch. Phys. Med. Rehabil. 2003, 84, 915 920. [CrossRef]

24. Kahn, L.; Lum, P.; Rymer, W.; Reinkensmeyer, D. Robot-assisted movement training for the stroke-impaired arm: Does it matter what the robot does? J. Rehabil. Res. Dev. 2006, 43, 619-630. [CrossRef]

25. Masiero, S.; Celia, A.; Rosati, G.; Armani, M.; Masieiro, S.; Celia, A.; Rosati, G.; Armani, M. Robotic-Assisted Rehabilitation of the Upper Limb After Acute Stroke. Arch. Phys. Med. Rehabil. 2007, 88, 142-149. [CrossRef]

26. Araújo, R.C.D. Desenvolvimento e Avaliação de Sistema de Auxílio à Reabilitação Motora do Membro Superior Após Acidente VasculaR EncefáLico. Doctoral Dissertation, Universidade Federal de Minas Gerais, Belo Horizonte - MG, Brazil, 2011.

27. Rúbio, G.P.; Ferreira, F.; de Lisboa Brandão, F.H.; Machado, V.; Tonelli, L.; Kozan, R.F.; Vimieiro, C. Design of Actuators Applied to a Upper Limb Orthosis. In Proceedings of the 25th International Congress of Mechanical Engineering, ABCM, Uberlandia, MG, Brazil, 20-25 October 2019. [CrossRef]

28. Radder, B.; Prange-Lasonder, G.B.; Kottink, A.I.R.; Holmberg, J.; Sletta, K.; van Dijk, M.; Meyer, T.; Melendez-Calderon, A.; Buurke, J.H.; Rietman, J.S. Home rehabilitation supported by a wearable soft-robotic device for improving hand function in older adults: A pilot randomized controlled trial. PLoS ONE 2019, 14, e0220544. [CrossRef]

29. Cherian, B.; Dominic, C.; G, V.; Vishakh, K.R. Exo-Glove: A Soft Wearable Robotic Hand for Stroke Survivors. Inte. Res. J. Eng. Technol. 2018, 05, 3358-3364.

30. Xiloyannis, M.; Galli, L.; Chiaradia, D.; Frisoli, A.; Braghin, F.; Masia, L. A Soft Tendon-Driven Robotic Glove: Preliminary Evaluation. In Converging Clinical and Engineering Research on Neurorehabilitation III. ICNR 2018. Biosystems E Biorobotics; Masia, L.; Micera, S.; Akay, M.; Pons, J.L., Eds.; Springer: Cham, Switzerland, 2019; pp. 329-333. [CrossRef]

31. Xiloyannis, M.; Cappello, L.; Dinh Binh Khanh.; Shih-Cheng Yen.; Masia, L. Modelling and design of a synergy-based actuator for a tendon-driven soft robotic glove. In Proceedings of the 2016 6th IEEE International Conference on Biomedical Robotics and Biomechatronics (BioRob), Singapore, 26-29 June 2016; pp. 1213-1219. [CrossRef]

32. Yurkewich, A.; Hebert, D.; Wang, R.H.; Mihailidis, A. Hand Extension Robot Orthosis (HERO) Glove: Development and Testing With Stroke Survivors With Severe Hand Impairment. IEEE Trans. Neural Syst. Rehabil. Eng. 2019, 27, 916-926. [CrossRef] [PubMed] 
33. Rocha, D.N. Desenvolvimento de um sistema de controle para a órtese funcional de mão da UFMG. Master's Thesis, Universidade Federal de Minas Gerais, Belo Horizonte, Brazil, 2007.

34. Wechsler, L.R.; Bates, D.; Stroemer, P.; Andrews-Zwilling, Y.S.; Aizman, I. Cell Therapy for Chronic Stroke. Stroke 2018, 49, 1066-1074. [CrossRef] [PubMed]

35. Freitas, P.P. Reabilitação da Mão, 1st ed.; Atheneu: São Paulo, Brazil, 2006; p. 578.

36. Fugl-Meyer, A.; Jaasko, L.; Leyman, I.; Olsson, S.; Steglind, S. The post-stroke hemiplegic patient: 1. A method for evaluation of physical performance. Scand. J. Rehab. Med. 1975, 7, 13-31.

37. Bohannon, R.W.; Smith, M.B. Interrater Reliability of a Modified Ashworth Scale of Muscle Spasticity. Phys. Ther. 1987, 67, 206-207. [CrossRef] [PubMed]

38. Bertolucci, P.H.; Brucki, S.M.; Campacci, S.R.; Juliano, Y. O Mini-Exame do Estado Mental em uma população geral: Impacto da escolaridade. Arquivos de Neuro-Psiquiatria 1994, 52, 01-07. [CrossRef]

39. Raghavan, P. Upper Limb Motor Impairment After Stroke. Phys. Med. Rehabil. Clin. North Am. 2015, 26, 599-610. [CrossRef]

40. Thompson, A.J.; Jarrett, L.; Lockley, L.; Marsden, J.; Stevenson, V. Clinical management of spasticity. J. Neurol. Neurosurg. Psychiatry 2005, 76, 459-463. [CrossRef]

41. Chagas, H.M.A. Determinação de valores de referência para a força de preensão palmar e força muscular respiratória em adultos saudáveis. Master's Thesis, Universidade de São Paulo, Brazil, 2018.

42. Bohannon, R. Muscle strength and muscle training after stroke. J. Rehabil. Med. 2007, 39, 14-20. [CrossRef]

43. Wu, W.T.; Chang, K.V.; Mezian, K.; Naňka, O.; Lin, C.P.; Özçakar, L. Basis of Shoulder Nerve Entrapment Syndrome: An Ultrasonographic Study Exploring Factors Influencing Cross-Sectional Area of the Suprascapular Nerve. Front. Neurol. 2018, 9. [CrossRef] [PubMed]

44. Wu, W.T.; Chang, K.V.; Mezian, K.; Naňka, O.; Yang, Y.C.; Hsu, Y.C.; Hsu, P.C.; Özçakar, L. Ulnar Wrist Pain Revisited: Ultrasound Diagnosis and Guided Injection for Triangular Fibrocartilage Complex Injuries. J. Clin. Med. 2019, 8, 1540. [CrossRef] [PubMed]

45. Faria-Fortini, I.; Michaelsen, S.M.; Cassiano, J.G.; Teixeira-Salmela, L.F. Upper Extremity Function in Stroke Subjects: Relationships between the International Classification of Functioning, Disability, and Health Domains. J. Hand Ther. 2011, 24, 257-265. [CrossRef] [PubMed]

(C) 2020 by the authors. Licensee MDPI, Basel, Switzerland. This article is an open access article distributed under the terms and conditions of the Creative Commons Attribution (CC BY) license (http:/ / creativecommons.org/licenses/by/4.0/). 